\title{
The Effect of Light Spectrum on the Morphology and Cannabinoid Content of Cannabis sativa $\mathrm{L}$.
}

\author{
Gianmaria Magagnini $^{a} \quad$ Gianpaolo Grassi $^{a}$ Stiina Kotiranta ${ }^{b}$ \\ ${ }^{a}$ Council for Agricultural Research and Economics, Research Centre for Cereal and Industrial Crops (CREA-CI), \\ Rovigo, Italy; bValoya Oy, Helsinki, Finland
}

\author{
Keywords \\ Cannabis sativa L. · LED · Light spectrum · Cannabinoid \\ content
}

\begin{abstract}
Cannabis sativa $\mathrm{L}$. flowers are the main source of $\Delta$-9tetrahydrocannabinol (THC) used in medicine. One of the most important growth factors in cannabis cultivation is light; light quality, light intensity, and photoperiod play a big role in a successful growth protocol. The aim of the present study was to examine the effect of 3 different light sources on morphology and cannabinoid production. Cannabis clones were grown under 3 different light spectra, namely high-pressure sodium (HPS), AP673L (LED), and NS1 (LED). Light intensity was set to $\sim 450 \mu \mathrm{mol} / \mathrm{m}^{2} / \mathrm{s}$ measured from the canopy top. The photoperiod was $18 \mathrm{~L}: 6 \mathrm{D} / 21$ days during the vegetative phase and 12L:12D/46 days during the generative phase, respectively. At the end of the experiment, plant dry weight partition, plant height, and cannabinoid content (THC, cannabidiol [CBD], tetrahydrocannabivarin [THCV], cannabigerol [CBG]) were measured under different light treatments. The experiment was repeated twice. The 3 light treatments (HPS, NS1, AP673L) resulted in differences in cannabis plant morphology and in cannabinoid content,
\end{abstract}

but not in total yield of cannabinoids. Plants under HPS treatment were taller and had more flower dry weight than those under treatments AP673L and NS1. Treatment NS1 had the highest CBG content. Treatments NS1 and AP673L had higher CBD and THC concentrations than the HPS treatment. Results were similar between experiments 1 and 2. Our results show that the plant morphology can be manipulated with the light spectrum. Furthermore, it is possible to affect the accumulation of different cannabinoids to increase the potential of medicinal grade cannabis. In conclusion, an optimized light spectrum improves the value and quality of cannabis. Current LED technology showed significant differences in growth habit and cannabinoid profile compared to the traditional HPS light source. Finally, no difference of flowering time was observed under different R:FR (i.e., the ratio between red and far-red light).

(C) 2018 The Author(s)

Published by S. Karger AG, Basel

\section{Introduction}

Cultivating Cannabis sativa L. (Cannabaceae) differs from other horticultural plants by the end product that is harvested. The total yield cannot be rated only by the weight of the flowers; the chemical composition of the

\begin{tabular}{|c|c|}
\hline KARGER & $\begin{array}{l}\text { (c) } 2018 \text { The Author(s) } \\
\text { Published by S. Karger AG, Basel }\end{array}$ \\
\hline $\begin{array}{l}\text { E-Mail karger@karger.com } \\
\text { www.karger.com/mca }\end{array}$ & $\begin{array}{l}\text { This article is licensed under the Creative Commons Attribution- } \\
\text { NonCommercial-NoDerivatives } 4.0 \text { International License (CC BY- } \\
\text { NC-ND) (http://www.karger.com/Services/OpenAccessLicense). } \\
\text { Usage and distribution for commercial purposes as well as any dis- } \\
\text { tribution of modified material requires written permission. }\end{array}$ \\
\hline
\end{tabular}


end product is also in the interest of the producers and end users. Different cannabis chemotypes contain numerous chemical compounds, such as cannabinoids, which are known to exert various pharmacological effects. Morphology and cannabinoid profile are dependent on genetic and environmental factors. For a medicinal cannabis producer, a continuous and uniform yield and production of a specific cannabinoid compound or a ratio between the different cannabinoids throughout the canopy and between growth cycles is important. Therefore, more and more professional medicinal cannabis producers are moving from greenhouses to indoors, into controlled and closed growth chambers. In growth chambers, it is possible to adjust temperature, humidity, light intensity, light spectrum, and air $\mathrm{CO}_{2}$ concentration. One of the most important growth factors in cannabis cultivation is light. Light quality, light intensity, and photoperiod play a significant role in a successful growth protocol. Growing indoors also improves the pest management and reduces the susceptibility of the crop to natural conditions, such as bad weather. In addition to the environmental factors, the regulatory authorities also increasingly push licensed producers towards producing, packaging, and labeling their products indoors at the producer's site. As said, indoor production offers the ability to cultivate year round under stable conditions resulting in up to 6 harvests per year. This makes indoor cropping 15-30 times more productive than outdoor cultivation [1]. Also, the historically illegal nature of cannabis has pushed the cultivation inside into artificial environments due to the fear of being caught committing a crime [2]. In addition to the positive effects of environmental control, indoor production minimizes the risk of cross-pollination with other nearby crops, particularly industrial hemp, to guarantee flowers without fertilization or seed maturation. On the other hand, indoor cannabis cultivation is energy intensive due to the high light demand and cooling of the closed environment. Cannabis is a plant adapted to high irradiance levels and warm temperatures. Chandra et al. [3] demonstrated that the highest photosynthetic efficiency was achieved under $\sim 1,500$ PPFD (Photosynthetic Photon Flux Density) and $25-30^{\circ} \mathrm{C}$; however, there is no evidence that a higher photosynthesis rate equals higher flower yields. It is also questionable whether such a high light intensity (1,500 PPFD) is economically feasible in terms of energy costs put into lighting and cooling. Indoor cannabis agriculture has in fact been classified as one of the "most energy intensive industries in the U.S." [4]. Lighting alone consumes $79-86 \%$ of the total electricity use $[5,6]$ in the cannabis farms. It has been cal- culated that $1 \%$ of the total energy consumption in the USA is for cannabis cultivation, and in top production states, such as California, the equivalent value is 3\% [6]. Often, cannabis production sites have separate facilities or rooms for each growth phase due to the different photoperiods and other environmental demands. There are 3 distinct phases in cannabis cultivation: propagation phase, vegetative growth phase, and flowering phase. In the interview study conducted by Sweet [7], it was noted that $600-1,000 \mathrm{~W}$ high-pressure sodium (HPS) lights were the most commonly used lighting source in Washington State during the flowering phase. In contrast, a wide variety of lighting types were reported to be used in the vegetative rooms, such as fluorescent light bulbs (CFL or T5), metal halide bulbs (MH), HPS lamps, induction bulbs, light-emitting diodes (LED), or a combination of different lighting types. During the propagation phase, the most commonly used lighting source is fluorescent light [8]. When using older technology, such as HPS or fluorescent light, the spectrum is seldom adjusted according to the plants' needs: the technology has been originally developed for totally different applications, such as street or office lighting. In the horticulture and crop science industry, it has been long known that one can manipulate plant morphology and metabolism with the light spectrum. For example, blue light has been shown to decrease internode length and enhance compactness of various species $[9,11]$, whereas far-red and green wavelengths have been shown to induce shade avoidance syndrome symptoms, including stem and leaf elongation and premature flowering [12]. A recently published paper from the Czech Republic also concluded that cannabis plants grown under a red and blue light spectrum had shorter internodes and a smaller leaf area compared to a white light source [13]. However, the paper does not give more specific information about the spectra used. In addition to morphological changes, light spectrum and irradiance level also have an impact on plant metabolism. The plant receives signals from the light environment through photoreceptors. Phytochromes, cryptochromes, phototropins, and UVR8 are the most well-studied photoreceptor groups found in higher plants. Phytochromes are the red- and far-red-sensing photoreceptors which regulate, for example, flowering, shade avoidance syndrome behavior, and germination in many species. Cryptochromes and phototropins are regulated mainly by blue and green wavelengths $[14,15]$. UVR8 is responsible for UV-B-induced responses. Short wavelength irradiation has been shown to enhance the plant defense mechanism by inducing metabolic activity, such as phenolic com-
Med Cannabis Cannabinoids 2018;1:19-27 DOI: $10.1159 / 000489030$
Magagnini/Grassi/Kotiranta 
pound synthesis. Phenolic compounds, including anthocyanins, found especially in red-colored leaves, have been shown to accumulate in lettuce leaves under short-wavelength blue and UV light. Many phenolic compounds are part of the plants' defense mechanism, which are synthesized under environmental stress. Short-wavelength irradiation and high photon flux irradiance are examples of light-related environmental stress. Several cannabinoids have also been suggested to be involved in the plant defense mechanism and to have antioxidant properties, including $\Delta$-9-tetrahydrocannabinol (THC) and cannabidiol (CBD) [16] as well as cannabigerol (CBG) [17]. Bouquet [18] hypothesized that cannabis resin has a protective sunscreen function. However, the glands and the secreted resin are accumulated on the lower leaf surface instead of the upper surface and in the perigonial bracts in the inflorescence which should be more susceptible to sun light [19]. While light quality may have an effect on the cannabinoid synthesis, cannabis yields are thought to strongly correlate with increasing light intensity $[3,20]$. However, light intensity did not seem to affect the cannabinoid concentration when plants were grown under different light intensities under HPS light $[21,22]$. In the studies by Vanhove et al. [22] and Potter and Duncombe [21], it was concluded that THC concentrations of flower material could be primarily linked to cannabis variety instead of cultivation method. In both studies, an increasing irradiance level correlated positively with flower dry weight, which resulted in higher total cannabinoid yield in the high irradiance treatments. However, the effects of different light qualities, or spectral composition, on cannabinoid synthesis and concentration in floral parts remain elusive. There are no recent light-related studies conducted with cannabis and based on cannabinoid profiles. However, already in very early studies in 1983, Mahlberg and Hemphill [23] concluded that in different light environments it was possible to manipulate the cannabinoid content of C. sativa L. measured in young leaves. The authors used colored filters to alter the light spectrum and concluded that the THC content of leaves from plants grown under shaded daylight and filtered red and blue light did not differ significantly from the THC content in daylight controls, while leaves from plants grown under filtered green light and darkness contained significantly lower levels of THC than those from plants grown in sunlight. The research and equipment at that time was not specific enough to thoroughly explain the effect of wavelength areas on cannabinoid content and the effect of lighting conditions on cannabis potency is still not clear. The first study related to light quality and cannabinoid content was conducted by Fairbairn and Liebann [24], who concluded that no increase of cannabinoids was found in a Nepalese variety grown in a greenhouse with or without supplemental lighting (HPS or UV lamps). Cannabis growers have been interested in UV light for a long time; however, the relationship between cannabinoids and UV-B is not as direct as first proposed. Increased concentrations of THC, but not of other cannabinoids, were found with UV-B treatment in both leaf and floral tissues of drug-type plants [20, 25]. In contrast, none of the cannabinoids in fiber-type plants were affected by UV-B radiation. In a more recent study, hemp leaves were exposed to UV-C radiation and analyzed for changes in secondary metabolite biosynthesis [26]. While no remarkable change in the cannabinoid content was observed, significant increases in dehydrostilbenes and cinnamic acid amide derivatives were found. The limited data available on the appropriate light source for cannabis production underscore the importance of studying technological developments in horticultural lighting. The objective of this study was to examine the effects of lightspectral quality on cannabis morphology and cannabinoid content in the female flowers under artificial growing conditions. Two lighting technologies (HPS and LED) and 3 different light spectra were used in this study.

\section{Materials and Methods}

Unrooted C. sativa L. cuttings, drug chemotype "G-170" (CREA-CI, Rovigo, Italy), were inserted into rockwool cubes (Grodan, Roermond, The Netherlands) and grown under T8 fluorescent lights (LUMILUX T8 36/840 and FLUORA T8 36W; Osram GmbH, Munich, Germany) for 2 weeks in a climate-controlled growth chamber. Light intensity during the rooting period was $\sim 160 \mu \mathrm{mol} / \mathrm{m}^{2} / \mathrm{s}$ measured with UPRTek PAR200 Spectrometer (UPRTek, Miaoli County, Taiwan). The spectral photon distribution of the fluorescent light source is shown in Figure 1. The cuttings were kept under $90 \%$ relative humidity at $25^{\circ} \mathrm{C}$ and exposed to $24 \mathrm{~h}$ of light. Cuttings were watered with clean tap water at the start of the rooting period. After 3 days, cuttings were supplemented daily with the complete fertilizer Coco A and B (5\% $\mathrm{NO}^{-}, 0.1 \% \mathrm{NH}^{+}, 4 \% \mathrm{P}_{2} \mathrm{O}_{5}, 3 \% \mathrm{~K}_{2} \mathrm{O}, 7 \% \mathrm{CaO}, 3 \% \mathrm{MgO}, 2 \% \mathrm{SO}_{3}$, $0.007 \%$ B, $0.001 \%$ Cu, 0.02\% Fe DTPA, 0.0003\% Fe EDTA, 0.01\% $\mathrm{Mn}, 0.002 \% \mathrm{Mo}, 0.007 \% \mathrm{Zn}, 0.5 \%$ fulvic and humic acid; CANNA International BV, Oosterhout, The Netherlands) with $1.5 \mathrm{mS} / \mathrm{cm}$ of electrical conductivity (EC) and $\mathrm{pH}$ 5.8. The adjustment of $\mathrm{pH}$ was done by $40 \%$ nitric acid. After rooting, plants were transplanted into 1.6-L pots containing coco peat (Coco Professional Plus, CANNA International BV) and acclimatized for 8 days in a grow room under HPS lights. Light intensity during the acclimatization period at canopy height was $40-50 \mu \mathrm{mol} / \mathrm{m}^{2} / \mathrm{s}$. During acclimatization, plants were irrigated with a fertilization solution of EC 1.8 $\mathrm{mS} / \mathrm{cm}$ and $\mathrm{pH}$ 5.8. After acclimatization period, 16 plants were placed under each light treatment in the growth boxes, 48 plants 


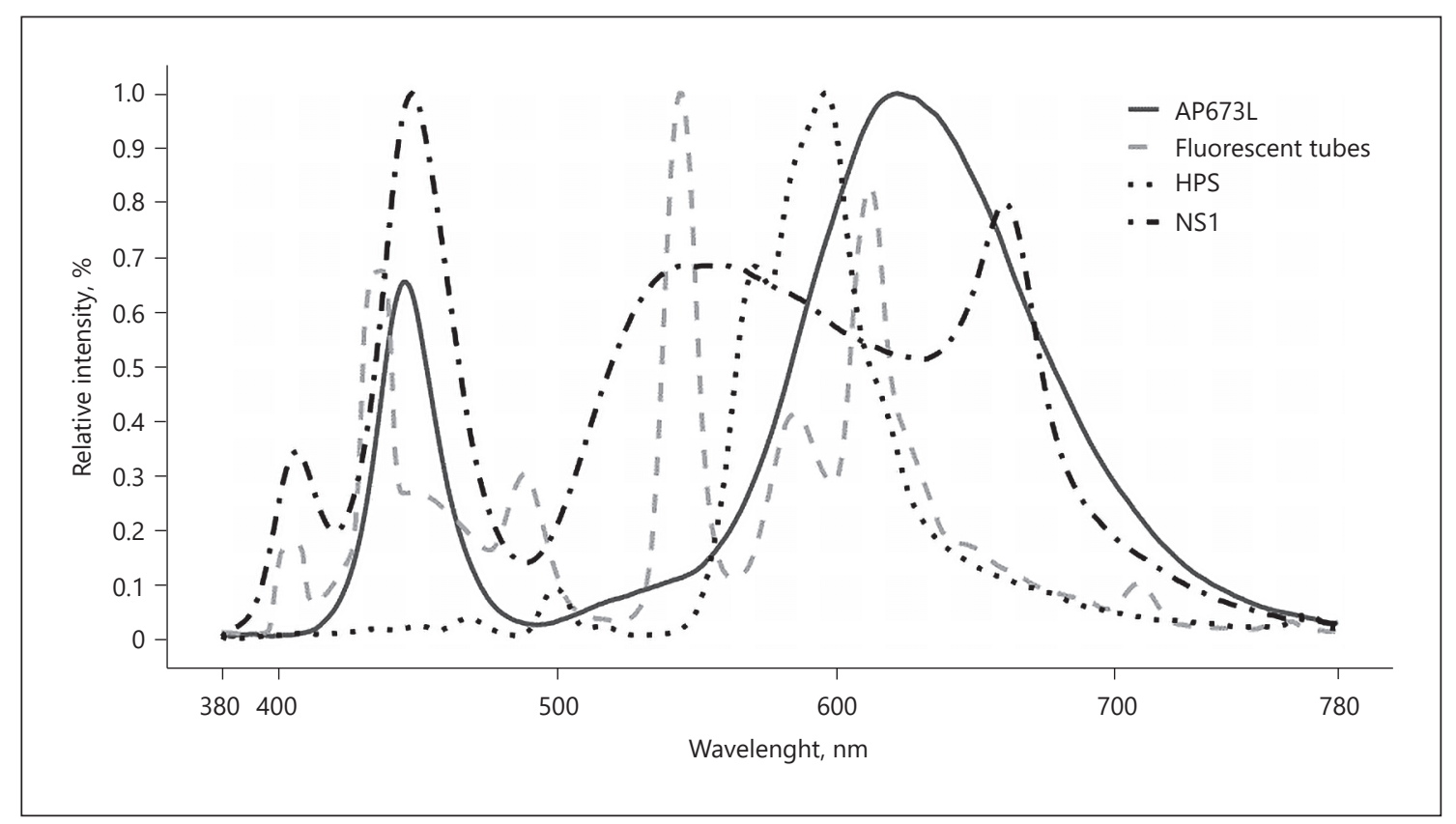

Fig. 1. Relative spectral photon flux of the light sources utilized.

Table 1. Spectral properties and the light intensities (in PAR, range 400-700 nm) under each light treatment

\begin{tabular}{llll}
\hline \multicolumn{4}{c}{ Light treatment } \\
\cline { 2 - 4 } & HPS & AP673L & NS1 \\
\hline $300-400$ & $1 \%$ & $0 \%$ & $2 \%$ \\
$400-500$ & $8 \%$ & $14 \%$ & $24 \%$ \\
$500-600$ & $68 \%$ & $20 \%$ & $37 \%$ \\
$600-700$ & $21 \%$ & $59 \%$ & $33 \%$ \\
$700-800$ & $3 \%$ & $7 \%$ & $4 \%$ \\
$400-700$ PAR & $96 \%$ & $93 \%$ & $94 \%$ \\
R:FR & 2.80 & 6.07 & 10.05 \\
B:G & 0.29 & 1.76 & 0.74 \\
B:R & 0.10 & 0.26 & 0.80 \\
\hline
\end{tabular}

NS1 and AP673L are LED lights; HPS, high-pressure sodium. R:FR and B:G ratios are calculated according to Sellaro et al. [44]: R:FR (650-670 nm/720-740 nm), B:G (420-490 nm/500-570 nm).

in total. Three different light sources were used in the experiment as treatments: 2 LED light spectra, AP673L and NS1 (B100, Valoya Oy; Helsinki, Finland), and 1 HPS light source (Philips Master TPIA Greenpower 600 W; Philips, Eindhoven, The Netherlands) with magnetic ballast (ETI, Madrid, Spain). Light fixtures were installed in grow tents $(1.2 \times 1.2 \times 2 \mathrm{~m})$ with a Mylar interior (DR120, Secret Jardin; Manage, Belgium), equipped with an air exhaust system to maintain the temperature at $26^{\circ} \mathrm{C}$ during the light phase and a relative humidity of $60-70 \%$ (Vents VK 125 , Vents, Kiev, Ukraine). The light irradiance level was measured to be $450 \mu \mathrm{mol} / \mathrm{m}^{2} / \mathrm{s}$ at canopy height when plants were transferred into the grow tents. Lamps were raised during the experiment as plants grew taller to maintain equal light intensities $(450 \mu \mathrm{mol} /$ $\mathrm{m}^{2} / \mathrm{s}$ in the range of $400-700 \mathrm{~nm}$ ) throughout the experiment. Percentages of wavelength areas in each spectrum are presented in Table 1. During the acclimatization and vegetative phases, the photoperiod was set to $18 \mathrm{~h}$ of light. The duration of the vegetative phase was 13 days. Out of the 16 plants in each treatment, 9 plants were selected for their good condition and uniformity and kept in the grow tents for another 46 days under a short photoperiod (12 $\mathrm{h}$ light and $12 \mathrm{~h}$ darkness) for flower induction. During the short photoperiod, EC of the nutrient solution was increased from 1.8 to $2.0 \mathrm{mS} / \mathrm{cm}$. The harvested plants were cut from the base and dried at $30^{\circ} \mathrm{C}$ by hanging them upside down in a dark room equipped with a dehumidifier. The plant height, stem weight, stem diameter, leaf biomass, and flower biomass were recorded from each plant. The floral cannabinoid concentrations (tetrahydrocannabivarin [THCV], THC, CBD, and CBG) were measured using gas chromatography (GC) according to the community method for the quantitative determination of THC content in hemp varieties (Reg. CE 796/2004) with some modifications. $40 \mathrm{mg}$ of cured and dried flower powder was weighed in a vial tube, and $4 \mathrm{~mL}$ of internal standard/extracting solution (ethanol with $0.01 \%$ of prazepam) was added. The sample was sonicated for $15 \mathrm{~min}$ at $65^{\circ} \mathrm{C}$, and the extract centrifuged at $12,000 \mathrm{rpm}$ for $5 \mathrm{~min}$; a $1-\mathrm{mL}$ aliquot of the extract was then transferred from the tube to a $2-\mathrm{mL}$ glass GC vial. GC analyses were performed using a SHIMADZU GC2010 PLUS equipped with an autosampler (H-TA srl. model HT 300 series) and a flame ionization detector (FID-2010 PLUS). The GC column was a $30 \mathrm{~m} \times 0.25 \mathrm{~mm}$ I.D. with $0.25-\mu \mathrm{m}$ film (RESTEK, 


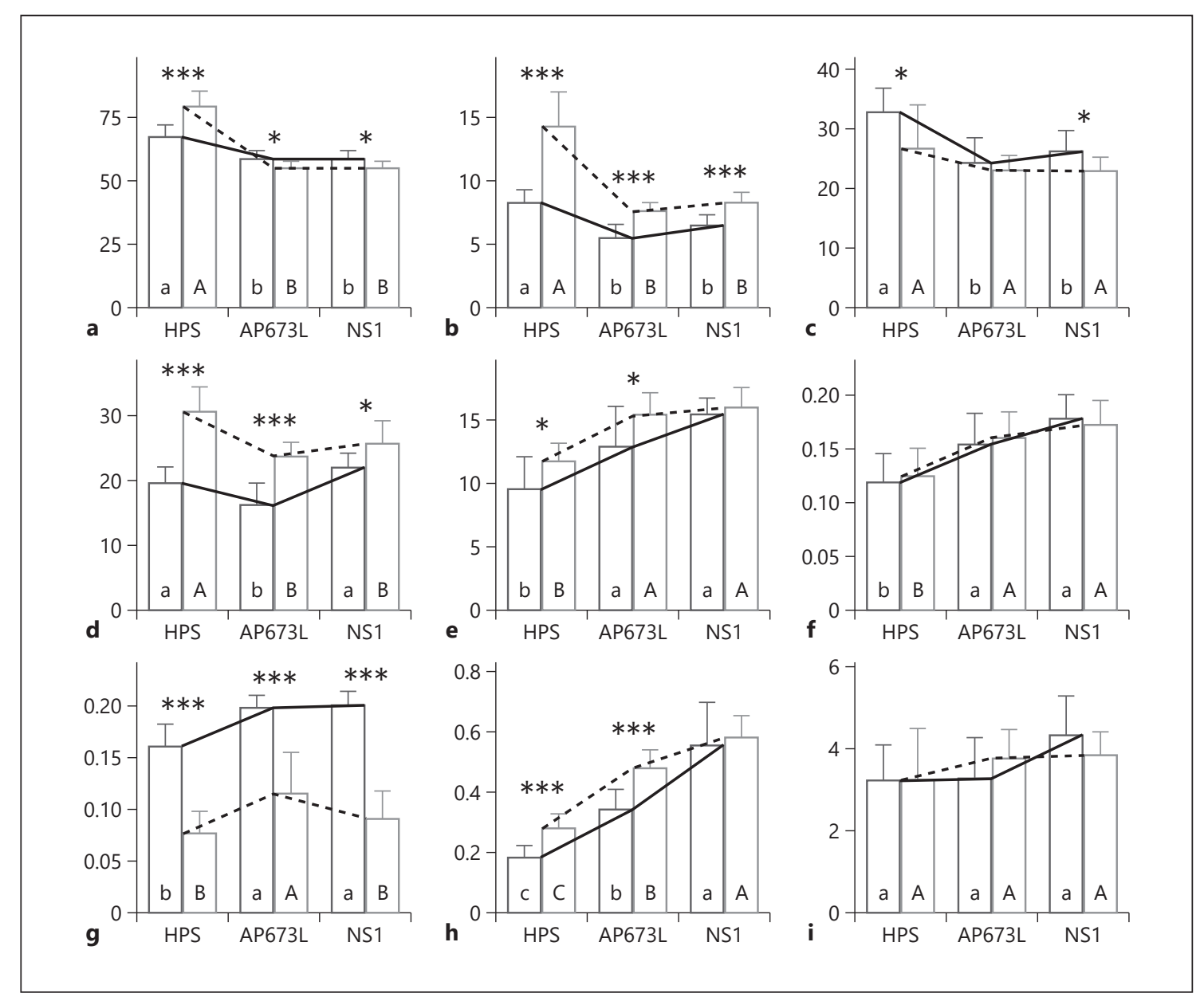

Fig. 2. Bar graphs (mean and standard deviation) of plant parameters evaluated. a Height (cm). b Stem (g/plant). c Flowers (g/plant). d Leaves (g/plant). e THC in flowers (\%). $\mathbf{f}$ CBD in flowers (\%). $\mathbf{g}$ THCV in flowers (\%). h CBG in flowers (\%). i Yield of cannabinoids (g/plant). Different letters inside the bars show significant differences (Tukey HSD, $p<0.05$ ). Solid lines and lower case letters are for trial 1 , and dashed lines and upper case letters are for trial 2. Significant differences between trials are represented by asterisks $\left(* p<0.05,{ }^{* *} p<0.01\right.$, *** $p<0.001)$.

model Rxi-5ms). Data were recorded using Labsolutions LC/GC 5.51 (SHIMADZU) software. GC conditions used for the determination of cannabinoids were: $\mathrm{H}_{2}$ at $30 \mathrm{~mL} / \mathrm{min}$ as carrier gas and $\mathrm{N}_{2}$ as make up gas at $40 \mathrm{~mL} / \mathrm{min}$, and air at $400 \mathrm{~mL} / \mathrm{min}$, respectively. The split flow rate was $15.8 \mathrm{~mL} / \mathrm{min}$, split ratio $25: 1$, pressure $12.76 \mathrm{psi}$, and purge flow rate $3 \mathrm{~mL} / \mathrm{min}$. $1-\mu \mathrm{L}$ injections were used; injector and detector temperatures were 280 and $300^{\circ} \mathrm{C}$, respectively. The isothermal oven temperature was $240^{\circ} \mathrm{C}$ and the total run time was $15 \mathrm{~min}$. Quantitation was achieved by determining peak area ratios of the analytes to the internal standard versus concentrations in the range of $7.8-500 \mu \mathrm{g} / \mathrm{mL}$. The growth experiment was repeated twice. The first experiment took place in April and May 2015 and the second experiment was conducted between February and April in 2016. The average temperature and relative humidity (mean \pm standard deviation) in the first experiment were $23.6 \pm 2.8^{\circ} \mathrm{C}$ and $64.5 \pm 14 \%$ for treatments AP673L and NS1 or $24.7 \pm 4.5^{\circ} \mathrm{C}$ and $56.1 \pm 14.8 \%$ for HPS, respectively; during the

Light Spectrum and Cannabis sativa L. second experiment they were $22.8 \pm 3.1^{\circ} \mathrm{C}$ and $61.9 \pm 9.9 \%$ for AP673L and NS1 or $23.6 \pm 3.8^{\circ} \mathrm{C}$ and $51.4 \pm 9.2 \%$ for HPS, respectively. Statistical analysis for comparison of the different light treatments was done using the Tukey test, with the level of significance at $5 \%$, while statistical comparisons between the experiments were performed with one-way analysis of variance (ANOVA) in RStudio environment (version 3.3.3, www.rstudio.com).

\section{Results and Discussion}

\section{Plant Morphology and Flower Yield}

The morphology of the flowering plants after 46 days of the short-day period differed significantly between the LED light treatments and the HPS treatment. Plants 
grown under NS1 and AP673L were shorter and more compact compared to those grown under the HPS treatment. The plants grown under HPS were significantly taller and had higher stem dry weight compared to those grown under the LED light treatments (Fig. 2a, b); no significant differences were found between the two LED spectra. Similar results between light treatments were found in both experiments; however, the differences in results between experiments were significant. In experiment 1 , plant height and dry stem weight ranged from $67.4 \mathrm{~cm}$ and $8.2 \mathrm{~g} /$ plant in HPS to $58.3 \mathrm{~cm}$ and $5.5 \mathrm{~g}$ in AP673L, respectively. In experiment 2, plant height and dry stem weight ranged from $79.2 \mathrm{~cm}$ and $14.2 \mathrm{~g}$ in HPS to $54.5 \mathrm{~cm}$ and $7.6 \mathrm{~g}$ in AP673L, respectively These results are consistent with previous studies by Tibbitts et al. [27] and Wheeler et al. [28], who reported that plants grown under sole HPS light may suffer from unbalanced morphology expressed by excessive leaf and stem elongation. This is due to the low R:FR ratio (i.e., the ratio between red and far-red light) and low blue light emission of the HPS lamp. The low R:FR ratio increases the activity of several transcription factors that activate genes involved in auxin biosynthesis leading to faster stem elongation [29]. Blue light regulates morphological responses such as shoot and internode elongation, shoot dry matter, and leaf area expansion [30]. The flower yield was affected by the light treatments. HPS plants had higher yields compared to the LED treatments in experiment 1 (Fig. 2c). In the second experiment, the differences between light treatments in flower yield were not statistically significant; however, the same tendency was present (Fig. 2c). The flower yields in the second experiment were 26.6, 23.1, and $22.8 \mathrm{~g}$ for HPS, AP673L, and NS1, respectively. The temperature variation between the two experiments may have played a role in the case of HPS and NS1 treatments in the yield results. Considering the AP673L treatment, no differences of dry flower weight was observed between experiments. Yields in the current study are consistent with the recent horticultural studies on cannabis [22], in which the yield per plant was $20.1 \mathrm{~g}$ under similar lighting conditions to the HPS treatment in this experiment. In experiment 1 , the highest leaf dry weight was measured in treatment NS1, ranging from $21.8 \mathrm{~g}$ (NS1) to $16.2 \mathrm{~g}$ (AP673L) (Fig. 2d). In the second experiment, HPS had the highest leaf dry weight, while the LED treatments did not have a significant difference between them. In experiment 2, the average leaf dry weight ranged from $30.6 \mathrm{~g}$ (HPS) to $23.6 \mathrm{~g}$ (AP673L). All light treatments showed significant differences between the two experiments and the experiments did not have a similar trend between experiments. No differences in flowering time between treatments were observed during the experiments. This suggests that the fast-growing "G-170" genotype is insensitive to changes in the R:FR ratio, a response commonly seen in long-day plants. No plant pathogens or nutrient deficiency were found during the experiments.

\section{Cannabinoid Yield}

HPS resulted in a significant decline of THC concentration in flowers compared to both LED treatments in both experiments, while no significant differences between the two LED types were observed. The amount of THC (\% w/w) was highest in treatment NS1 and lowest in treatment HPS in both experiments 1 and 2 (Fig. 2e). In experiment 1 , HPS had $38 \%$ less $(9.5 \%)$ THC compared to NS1 (15.4\%), in experiment 2, the equivalent number was $26 \%$. One-way ANOVA between the two experiments showed a slight but significant $(p<0.05)$ difference in the THC concentration in treatments HPS and AP673L but not in treatment NS1. The drop in the THC concentration under HPS led to a corresponding decrease in CBD, THCV, and especially CBG, which consequently resulted in a significant increase in the THC proportion compared to the LED treatments. HPS had a higher proportion of THC in the total cannabinoid content $(95.3 \%$ in the first experiment and $96.0 \%$ in the second experiment) compared to NS1 (94.3 and 94.9\%). Moreover, comparison between experiments showed a strong difference in the THC proportion under HPS and a slight but significant $(p<0.05)$ difference in NS1, but not in AP673L. The average $\mathrm{CBD}$ concentration showed a similar pattern to the THC concentration (Fig. 2f). The CBD concentration was highest in the LED treatments and lowest in the HPS treatment in both experiments. In experiment 1 , HPS had 35\% less (0.1\%) CBD compared to NS1 (0.2\%). In experiment 2 , the equivalent number was $29 \%$. There were no significant differences in CBD concentrations between the experiments in any of the light treatments. In experiment 1 , the THCV concentration was significantly higher in treatments AP673L (0.2\%) and NS1 (0.2\%) compared to HPS (0.2\%) (Fig. $2 \mathrm{~g}$ ). In experiment 2 , the THCV concentrations in all treatments were significantly lower than in experiment 1 . AP673L resulted in the highest concentration of THCV (0.1\%), which was $35 \%$ more than in the HPS treatment $(0.1 \%)$ and $21 \%$ more than in the NS1 treatment $(0.1 \%)$. In experiment 1 , the average THCV purity showed no significant relationship between light treatments and ranged from $1.7 \%$ under HPS to $1.2 \%$ under NS1. In experiment 2, NS1 treatment resulted in a lower THCV proportion (0.5\%) compared
Med Cannabis Cannabinoids 2018;1:19-27 DOI: $10.1159 / 000489030$
Magagnini/Grassi/Kotiranta 
to HPS $(0.6 \%)$ or AP673L (0.7\%) (data not shown). There was a strong and significant difference in the THCV content and proportion values between the experiments in all light treatments. Data obtained from this study indicate that the light spectrum has an effect on the biosynthesis of CBG (Fig. 2h). The CBG concentration was highest in the NS1 treatment in both experiments. NS1 had 207 and $107 \%$ more CBG compared to the HPS treatment in experiments 1 and 2, respectively, and 63 and $21 \%$ more than AP673L in experiments 1 and 2, respectively. In the HPS and AP673L treatments, the results differed significantly $(p<0.001)$ between the two experiments. CBG proportion also showed a similar pattern to $\mathrm{CBG}$ content. The NS1 treatment had the highest CBG purity in both experiments (3.4 and 3.5\%), followed by AP673L (2.6 and $2.9 \%)$ and HPS (1.8 and 2.3\%). There were significant differences in CBG proportion among the experimental trials under the AP673L $(p<0.05)$ and HPS lamps $(p<0.01)$, but not under NS1. There were no significant differences found in the total yield of cannabinoids between the light treatments or between the two experiments (Fig. 2i). In experiment 1 , the highest cannabinoid yield per plant was recorded under NS1 (4.3 g/plant) and the lowest under HPS ( $3.2 \mathrm{~g} /$ plant). In experiment 2 , results were following a similar pattern and the highest cannabinoid yield was in the NS1 treatment (3.8 g) and the lowest in the HPS treatment $(3.3 \mathrm{~g})$.

The first enzyme in the cannabinoid pathway is a type III PKS, named tetraketide synthase (TKS), which requires the presence of a polyketide cyclase enzyme, named olivetolic acid cyclase (OAC) to form olivetolic acid (OA) [31]. OA reacts with geranyl pyrophosphate (GPP) by GPP:olivetolate geranyltransferase, named CBGA synthase (CBGAS), to form CBGA [32], which is converted by oxidocyclase enzymes to the major cannabinoids THCA and CBDA, the biogenic acids of THC and CBD [33]. Unfortunately, no data are available regarding the expression regulation of these genes. In higher plants, the chalcone synthase (CHS) superfamily, a well-studied plant type III PKS, is substantially light induced, resulting in a variety of polyphenol scaffold accumulations [34]. Plants have evolved a complex photoreceptor system to perceive red and far-red (phytochromes), green, blue, UV-A (cryptochromes, phototropins, ZTL/FKF1/LKP2), and UV-B light (UVR8) [35]. Photoreceptors activate various signal transduction cascades to regulate light-dependent responses via transcriptional factors and related gene expression. For example, shorter wavelengths, in the range of blue and UV light, are found to be the most effective in the accumulation of anthocyanins and flavo-

Light Spectrum and Cannabis sativa L. noids, often by increasing the expression of flavonoid pathway genes or transcription factors [36,37]. Strawberries treated with blue light showed a significant increase in anthocyanin content and transcript levels of $\mathrm{FaCHS}$, a key enzyme in the biosynthesis of flavonoid and anthocyanins [38]. In the same study, using overexpression, it was shown that phototropin (PHOT2) was involved in blue light-induced anthocyanin accumulation. Also, cryptochromes (CRY1 and CRY2) control the blue lightinduced anthocyanin accumulation response $[39,40]$. In the present study, the highest CBG and THC concentrations were measured in the NS1 treatment, which had the highest portion of blue and UV-A wavelengths in the spectrum compared to the other treatments. Blue and UV wavelengths have been previously reported to have a positive effect on the synthesis of many secondary metabolites in multiple species [30]. Mahlberg and Hemphill [23] studied the effect of light intensity and light quality on cannabinoid content in plants grown in greenhouse conditions with altered spectra using different colored filters. They concluded that a higher light intensity increased the amount of THC, CBC, and CBN. According to their data, blue and red light positively affected the THC accumulation in leaves, whereas a green or dark environment had a negative impact compared to the control treatment (natural light). In the present study, the highest THC content measured in the flowers was under the NS1 treatment and the lowest was under HPS. We suggest that the blue and UV-A wavelengths positively affected THC synthesis in treatments NS1 and AP673L, whereas the lack of blue and UV-A irradiation in the HPS treatment resulted in a lower amount of THC in flowers. The amount of blue and UV-A irradiation was highest in the NS1 treatment; however, the THC level difference between AP673L and NS1 was not significant. This result could partially be explained by the high amount of green irradiation in the NS1 treatment, which can negatively affect the THC synthesis as also shown in the experiment by Mahlberg and Hemphill [23]. Green light has also been shown to act antagonistically to other blue light-induced responses, such as stomatal closure [41] or anthocyanin accumulation [42]. Another possible cause of drop in cannabinoid concentration under the HPS lamp was the low R:FR ratio. The R:FR ratio is known to play a key role in the shade avoidance syndrome in plants through the mediation of phytochromes [43]. In shaded conditions, plant photoreceptors activate shade-avoidance responses and reduce the expression of the jasmonic acid signaling pathway and other phytochemical biosynthesis, such as soluble phenolics, anthocyanins, glucosinolates, and terpenoids 
[29]. Our results suggest that manipulation of light quality during the flowering phase could be a useful tool to improve the yield of THC and other cannabinoids in cannabis cultivation. We suggest that other complex mechanisms mediated by the UV-A and blue wavelengths may act synergistically to induce CBG accumulation in cannabis flowers, CBG being the precursor of other cannabinoids.

\section{Conclusion}

These two experiments are part of a trial series aimed to study the effect of light conditions on cannabis growth. In conclusion, the experiments presented here demonstrate that the optimal spectrum for a specific photoperiod scheme may have diverse beneficial effects on cannabis growth, yield, and cannabinoid profile. Our study shows that the light environment plays an important role not only in plant size and stature but also in the accumulation of cannabinoids. During a long photoperiod, a low R:FR ratio is preferable to make more developed long cuttings, while during a short photoperiod a high proportion of blue irradiation is suitable to improve the medicinal value of cannabis in terms of cannabinoid content. Manipulation of the spectrum, an advantage of the LED technology, offers better space utilization to support the heating and cooling loads of growing buildings. LED lighting strategies may be applied to improve the energy utilization and carbon footprint of cannabis crop. The mechanisms underlying the effect of UV-A/blue light wavelength on cannabinoid pathways require further elucidation.

\section{Acknowledgment}

The authors gratefully acknowledge all the staff members involved in the study. This work was supported by fundings from Valoya Oy.

\section{Disclosure Statement}

The authors declare that Valoya has funded the research activity. Dr. Stiina Kotiranta is employed at Valoya company.

\section{References}

1 UNODC: World Drug Report 2009. New York: United Nations Publications, 2009. Available from: http://www.unodc.org/documents/wdr/WDR_2009/WDR2009_eng_ web.pdf.

2 Potter GR, Barratt MJ, Malm A, Bouchard M, Blok T, Christensen A-S, Klein A: Global patterns of domestic cannabis cultivation: sample characteristics and patterns of growing across eleven countries. Int J Drug Policy 2015;26:226-237.

3 Chandra S, Lata H, Khan IA, Elsohly MA: Photosynthetic response of Cannabis sativa $\mathrm{L}$. to variations in photosynthetic photon flux densities, temperature and $\mathrm{CO} 2$ conditions. Physiol Mol Biol Plants 2008;14:299-306.

4 Warren GS: Regulating pot to save the polar bear: energy and climate impacts of the marijuana industry. Columbia J Environ Law 2015;40:385.

5 Arnold JM: Energy consumption and environmental impacts associated with cannabis cultivation; PhD thesis, Humboldt State University, 2013

6 Mills E: The carbon footprint of indoor cannabis production. Energy Policy 2012;46:5867.

7 Sweet SL: The energy intensity of lighting used for the production of recreational cannabis in Washington State and implications for energy efficiency; $\mathrm{PhD}$ thesis, Evergreen State College, 2016.
8 Chandra S, Lata H, ElSohly MA, Walker LA, Potter D: Cannabis cultivation: methodologi$\mathrm{cal}$ issues for obtaining medical-grade product. Epilepsy Behav 2017;70(Pt B):302-312.

9 Dong C, Fu Y, Liu G, Liu H: Growth, photosynthetic characteristics, antioxidant capacity and biomass yield and quality of wheat (Triticum aestivum $\mathrm{L}$.) exposed to LED light sources with different spectra combinations. J Agron Crop Sci 2014;200:219-230.

$10 \mathrm{Wu}$ Q, Su N, Shen W, Cui J: Analyzing photosynthetic activity and growth of Solanum lycopersicum seedlings exposed to different light qualities. Acta Physiol Plant 2014;36: 1411-1420.

11 Khan MA, Marwat KB: The effects of light quality and temperature on the growth and development of geraniums. Pak J Bot 2011;43: 679-688.

12 Franklin KA, Whitelam GC: Phytochromes and shade-avoidance responses in plants. Ann Bot 2005;96:169-175.

13 Lalge A, Cerny P, Trojan V, Vyhnanek T: The effects of red, blue and white light on the growth and development of Cannabis sativa L. Mendel Net, November 8-9, 2017, pp 646651.

14 Briggs WR, Christie JM: Phototropins 1 and 2 : versatile plant blue-light receptors. Trends Plant Sci 2002;7:204-210.
15 Cashmore AR, Jarillo JA, Wu Y-J, Liu D: Cryptochromes: blue light receptors for plants and animals. Science 1999;284:760765 .

16 Hampson AJ, Grimaldi M, Lolic M, Wink D, Rosenthal R, Axelrod J: Neuroprotective antioxidants from marijuana. Ann NY Acad Sci 2000;899:274-282.

17 Giacoppo S, Gugliandolo A, Trubiani O, Pollastro F, Grassi G, Bramanti P, Mazzon E: Cannabinoid CB2 receptors are involved in the protection of RAW264.7 macrophages against the oxidative stress: an in vitro study. Eur J Histochem 2017;61:2749.

18 Bouquet R: Cannabis. Bull Narcotics 1950;4: 14-30.

19 Small E: Evolution and classification of Cannabis sativa (marijuana, hemp) in relation to human utilization. Bot Rev 2015;81:189-294.

20 Lydon J, Teramura AH, Coffman CB: UV-B radiation effects on photosynthesis, growth and cannabinoid production of two Cannabis sativa chemotypes. Photochem Photobiol 1987;46:201-206.

21 Potter DJ, Duncombe P: The effect of electrical lighting power and irradiance on indoorgrown cannabis potency and yield. J Forensic Sci 2012;57:618-622.

22 Vanhove W, Van Damme P, Meert N: Factors determining yield and quality of illicit indoor cannabis (Cannabis spp.) production. Forensic Sci Int 2011;212:158-163. 
23 Mahlberg PG, Hemphill JK: Effect of light quality on cannabinoid content of Cannabis sativa L. (Cannabaceae). Botan Gaz 1983;144: $43-48$.

24 Fairbairn JW, Liebmann JA: The cannabinoid content of Cannabis sativa L grown in England. J Pharm Pharmacol 1974;26:413-419.

25 Pate DW: Chemical ecology of cannabis. J Ind Hemp Assoc 1994;2:32-37.

26 Marti G, Schnee S, Andrey Y, Simoes-Pires C, Carrupt P-A, Wolfender J-L, Gindro K: Study of leaf metabolome modifications induced by UV-C radiations in representative Vitis, Cissus and Cannabis species by LC-MS based metabolomics and antioxidant assays. Molecules 2014;19:14004-14021.

27 Tibbitts TW, Morgan DC, Warrington IJ: Growth of lettuce, spinach, mustard, and wheat plants under four combinations of high-pressure sodium, metal halide, and tungsten halogen lamps at equal PPFD. J Amer Soc Hort Sci 1983;108:622-630.

28 Wheeler RM, Mackowiak CL, Sager JC: Soybean stem growth under high-pressure sodium with supplemental blue lighting. Agron J 1991;83:903-906.

29 Ballaré CL: Light regulation of plant defense. Annu Rev Plant Biol 2014;65:335-363.

30 Huché-Thélier L, Crespel L, Le Gourrierec J, Morel P, Sakr S, Leduc N: Light signaling and plant responses to blue and UV radiations perspectives for applications in horticulture. Environ Exp Bot 2016;121:22-38.
31 Gagne SJ, Stout JM, Liu E, Boubakir Z, Clark SM, Page JE: Identification of olivetolic acid cyclase from Cannabis sativa reveals a unique catalytic route to plant polyketides. Proc Natl Acad Sci 2012;109:12811-12816.

32 Fellermeier M, Zenk MH: Prenylation of olivetolate by a hemp transferase yields cannabigerolic acid, the precursor of tetrahydrocannabinol. FEBS Lett 1998;427:283-285.

33 Sirikantaramas S, Taura F, Morimoto S, Shoyama Y: Recent advances in Cannabis sativa research: biosynthetic studies and its potential in biotechnology. Curr Pharm Biotechnol 2007;8:237-243.

34 Flores-Sanchez IJ, Verpoorte R: PKS activities and biosynthesis of cannabinoids and flavonoids in Cannabis sativa L. plants. Plant Cell Physiol 2008;49:1767-1782.

35 Hong Y, Yang L, Li M, Dai S: Comparative analyses of light-induced anthocyanin accumulation and gene expression between the ray florets and leaves in chrysanthemum. Plant Physiol Biochem 2016;103:120-132.

36 Siipola SM, Kotilainen T, Sipari N, Morales LO, Lindfors AV, Robson T, Aphalo PJ: Epidermal UV-A absorbance and whole-leaf flavonoid composition in pea respond more to solar blue light than to solar UV radiation. Plant Cell Environ 2015;38:941-952.

37 Zoratti L, Karppinen K, Escobar AL, Häggman H, Jaakola L: Light-controlled flavonoid biosynthesis in fruits. Front Plant Sci 2014;5: 543.
38 Kadomura-Ishikawa Y, Miyawaki K, Noji S, Takahashi A: Phototropin 2 is involved in blue light-induced anthocyanin accumulation in Fragaria $\times$ ananassa fruits. J Plant Res 2013;126:847-857.

39 Giliberto L, Perrotta G, Pallara P, Weller JL, Fraser PD, Bramley PM, Giuliano G: Manipulation of the blue light photoreceptor cryptochrome 2 in tomato affects vegetative development, flowering time, and fruit antioxidant content. Plant Physiol 2005;137:199-208.

40 Sharma P, Chatterjee M, Burman N, Khurana JP: Cryptochrome 1 regulates growth and development in Brassica through alteration in the expression of genes involved in light, phytohormone and stress signalling. Plant Cell Environ 2014;37:961-977.

41 Frechilla S, Talbott LD, Bogomolni RA, Zeiger E: Reversal of blue light-stimulated stomatal opening by green light. Plant Cell Physiol 2000;41:171-176.

42 Zhang T, Folta KM: Green light signaling and adaptive response. Plant Signal Behav 2012;7: 75-78.

43 Demotes-Mainard S, Péron T, Corot A, Bertheloot J, Le Gourrierec J, Pelleschi-Travier S, Boumaza R: Plant responses to red and farred lights, applications in horticulture. Environ Exp Bot 2016;121:4-21.

44 Sellaro R, Crepy M, Trupkin SA, Karayekov E, Buchovsky AS, Rossi C, Casal JJ: Cryptochrome as a sensor of the blue/green ratio of natural radiation in Arabidopsis. Plant Physiol 2010;154:401-409. 